\title{
Role of Serine 286 in cosubstrate binding and catalysis of a flavonol O-methyltransferase
}

\author{
Jack Kornblatt, Ingrid Muzac, Yoongho Lim, Joong Hoon Ahn, and \\ Ragai K. Ibrahim
}

\begin{abstract}
O$-Methyltransferases catalyze the transfer of the methyl groups of $S$-adenosyl-L-methionine to specific hydroxyl groups of several classes of flavonoid compounds. Of the several cDNA clones isolated from a Chrysosplenium americanum library, FOMT3' encodes the 3'/5'-O-methylation of partially methylated flavonols. The recombinant protein of another clone, FOMTX which differs from FOMT3' by a single amino acid residue (Ser286Arg) exhibits no enzymatic activity towards any of the flavonoid substrates tested. Replacement of Ser 286 in FOMT3' with either Ala, Leu, Lys or Thr, almost abolished $O$-methyltransferase activity. In contrast with FOMT3', no photoaffinity labeling could be achieved using $\left[{ }^{14} \mathrm{CH}_{3}\right]$ AdoMet with the mutant recombinant proteins indicating that Ser 286 is also required for cosubstrate binding. These results are corroborated by isothermal titration microcalorimetry measurements. Circular dichroism spectra ruled out any significant conformational differences in the secondary structures of both FOMT3' and Ser286Arg. Modeling FOMT3' on the structure of chalcone methyltransferase indicates that serine 286 is greater than $10 \AA$ from any of the residues of the active site or the AdoMet binding site of FOMT3'. At the same time, residues 282 to 290 are conserved in most of the Chrysosplenium americanum OMTs. These residues form a large part of the subunit interface, and at least five of these residues are within $4 \AA$ of the opposing subunit. It would appear, therefore, that mutations in Ser 286 exert their influence by altering the contacts between the subunits and that these contacts are necessary for maintaining the integrety of the AdoMet binding site and active site of this group of enzymes.
\end{abstract}

Key words: flavonoids, $O$-methyltransferase, photoaffinity labeling.

Résumé : Les $O$-méthyltransférases (OMTs) catalysent le transfert de groupes méthyles de la $S$-adénosyl-méthionine sur des groupes hydroxyles spécifiques de plusieurs classes de flavonoïdes. Parmi plusieurs clones d'ADNc isolés d'une banque de Chrysosplenium amiricanum, le FOMT3' code une enzyme catalysant la $3^{\prime}-5^{\prime}$-O-méthylation de flavonols partiellement méthylés. La protéine recombinante issue d'un autre clone, FOMTx, qui ne diffère de FOMT3' que par un seul acide aminé (Ser286Arg), ne démontre aucune activité enzymatique envers les substrats flavonoïdes testés. Le remplacement de la Ser286 de FOMT3' par une Ala, Leu, Lys ou Thr abolit presque totalement l'activité $O$-méthyltransférase. Contrairement à la FOMT3', aucun marquage par photoaffinité n'est obtenu avec le $\left[{ }^{14} \mathrm{CH}_{3}\right]$ AdoMet sur les protéines recombinantes mutantes, indiquant que la Ser286 est aussi requise pour la liaison du co-substrat. Ces résultats sont corroborés par des mesures de titration microcalorimétrique isothermique. Le spectre en dichroïsme circulaire exclut toute différence de conformation significative dans la structure secondaire de FOMT3' et le mutant Ser286Arg. La modélisation de FOMT3' sur la structure de la chalcone méthyltransférase indique que la sérine 286 est éloignée de plus de $10 \AA ̊$ de n'importe quel résidu du site actif ou du site de liaison de l'AdoMet de FOMT3'. Parallèlement, les résidus 282 à 290 sont conservés dans la plupart des OMTs de Chrysosplenium americanum. Ces résidus forment une large part de l'interface de la sous-unité, et au moins cinq de ces résidus sont à moins de 4 A de la sous-unité opposée. Il semblerait donc que la mutation de la Ser286 exerce son influence en affectant les contacts entre les sous-unités et que ces contacts sont nécessaires pour maintenir l'intégrité du site de liaison de l'AdoMet et du site actif de ce groupe d'enzyme.

Mots clés : Flavonoïdes, $O$-méthyltransférases, marquage par photoaffinité.

[Traduit par la Rédaction]

Received 29 December 2003. Revision received 4 May 2004. Accepted 14 May 2004. Published on NRC Research Press Web site at http://bcb.nrc.ca on 24 August 2004.

Abbreviations: AdoMet, $S$-adenosyl-L-methionine; CD, circular dichroism; FOMT3', flavonol 3'- $O$-methyltransferase; ITC, isothermal titration calorimetry; OMT, $O$-methyltransferase; TMQ, 3,7,4'-trimethylquercetin.

J. Kornblatt. Biology Department's Centre for Structural and Functional Genomics, Concordia University, 7141 Sherbrooke Street West, Montreal, QC H4B 1R6, Canada.

I. Muzac and R.K. Ibrahim. ${ }^{1}$ Plant Biochemistry Laboratory, Concordia University, 7141 Sherbrooke Street West, Montreal, QC H4B 1R6, Canada.

Y. Lim and J.H. Ahn. Bio/Molecular Informatics Centre, Konkuk University, Seoul 143-701, Korea.

${ }^{1}$ Corresponding author (e-mail: ragibra@vax2.concordia.ca). 


\section{Introduction}

Flavonoid compounds are one of the most ubiquitous groups of natural plant products, and they play important roles in the biochemistry, physiology, and ecology of plants (Bohm 1998). Flavonoid $O$-methyltransferases (FOMTs) catalyze the transfer of the methyl groups of $S$-adenosyl-Lmethionine (AdoMet) to specific hydroxyl groups in a variety of flavonoid compounds, including chalcones, flavanones, flavones, isoflavones, and flavonols. Several of the $O$ methyltransferase (OMT) cDNA clones have been isolated and characterized (for review, see Ibrahim and Muzac 2000). The $O$-methylation of flavonoids not only reduces the chemical reactivity of their phenolic hydroxyl groups, but also increases their lipophilicity and antimicrobial/antiviral activity (French et al. 1991), it reduces their mutagenicity, and prevents angiogenesis, which is responsible for tumor propagation in mammalian tissues (Zhu et al. 1994).

We previously isolated several flavonol OMT cDNA clones from a Chrysosplenium americanum (Saxifragaceae) shootexpression library (Fig. 1). One of these clones, FOMT3', was shown to encode the $3^{\prime} / 5^{\prime}$-OMT for 3,7,4'-trimethylquercetn (TMQ) (Gauthier et al. 1996). Another clone, FOMTX, was identical to FOMT3', except for a single aminoacid substitution at position 286 in the amino-acid sequence (Ser286Arg, Fig. 1), but its recombinant protein exhibits no enzymatic activity towards any of the flavonoids tested. Substituting Arg for Ser in FOMT3' abolished activity, and substituting Ser for Arg in FOMTx restored activity. Aminoacid sequence alignment of 16 putative FOMT cDNA clones from C. americanum (Fig. 1) indicates that Ser 286 is conserved in 11 of the 16 sequences, and is substituted by Arg in FOMTX, and by Thr in four other clones. Two of the latter, clones $\mathrm{m}$ and $\mathrm{n}$ (Fig. 1), previously known as OMT1 and OMT2, respectively, exhibited pronounced "promiscuity"; they did not accept TMQ, but used both phenylpropanoids and flavonoids as substrates, albeit with different efficiencies (Gauthier et al. 1998), which indicates that replacement of Ser286 with Thr results in a drastic change in substrate preference. Replacement of Ser286 in FOMT3' with Ala, Leu, Lys, or Thr greatly reduced, and in some cases abolished, enzyme activity. This suggests that Ser 286 is an important amino acid in FOMTs, and one in which mutation to other residues abolishes the catalytic activity of its gene product. Several publications have reported the effect of single aminoacid changes on the catalytic activity/functionality (Hu et al. 1998; Iwano et al. 1997; Kittendorf et al. 2003; McKinney and Cravett 2003; Pollock and Barber 2000), substrate specificity (Hofsteenge et al. 1998; Johnson et al. 2001; Schröder and Schröder 1992; Mayer et al. 2000), or both catalysis and substrate specificity (Yamamoto and McNeill 1996) of a variety of enzyme proteins.

This report investigates the molecular basis of the need for Ser286 for the AdoMet binding and catalysis of FOMT3', using a combination of experimental and theoretical approaches. Experimentally, we used site-directed mutagenesis, circular dichroism spectroscopy, isothermal microcalorimetry, and photoaffinity-labeling techniques. In addition, molecular modeling of FOMT3', using chalcone OMT (ChOMT) (Zubieta et al. 2001) as a template, was employed to determine the role of Ser286 in cosubstrate binding and catalysis.
Fig. 1. Alignment of part of the amino-acid sequence of 16 putative OMT cDNA clones isolated from a Chrysosplenium americanum shoot library. Notice that Ser286 is conserved in 11 clones, and replaced with Arg in OMTx and with $\mathrm{Thr}$ in clones $\mathrm{m}$ to $\mathrm{r}$.

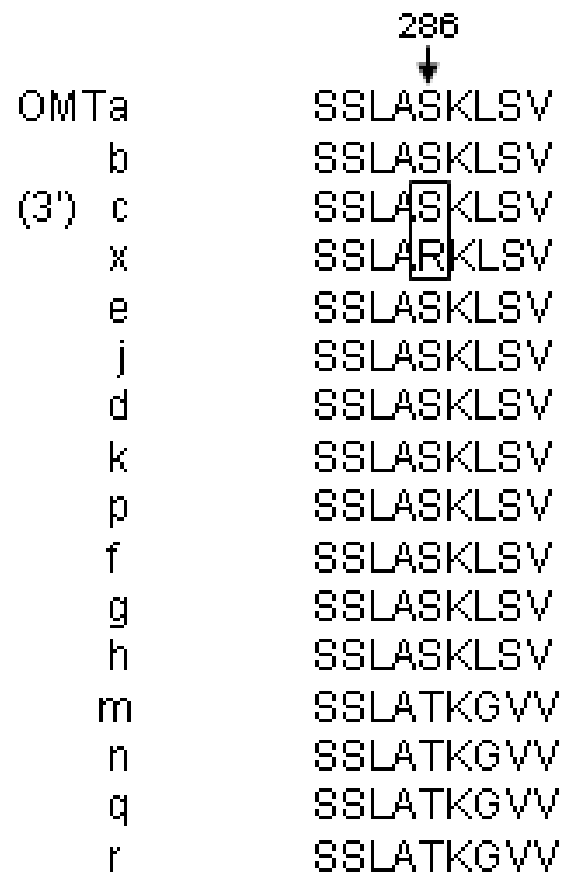

\section{Materials and methods}

\section{cDNA clones and site-directed mutagenesis}

FOMT3' (GenBank accession No. U16794) and Ser286Arg cDNA clones were previously isolated and cloned in the pTRCHis vector (Invitrogen, Carlsbad) to produce a fusion protein containing a His-tag (Gauthier et al. 1996). Sitedirected mutagenesis of specific amino acids was carried out using the QuickChange Site-Directed Mutagenesis kit (Stratagene, La Jolla, Calif.), in accordance with manufacturer's instructions, and the FOMTX (Ser286Arg) clone was used as a template. The fidelity of the mutation was confirmed by the DNA sequencing of the mutated constructs.

\section{Expression and purification of recombinant proteins}

All enzyme proteins were expressed as described elsewhere (Séguin et al. 1998). A single bacterial colony from each confirmed mutant was grown in Luria-Bertani (LB) medium, containing $100 \mu \mathrm{g} \cdot \mathrm{mL}^{-1}$ ampicillin, and expression of the fusion proteins was induced with the addition of $1 \mathrm{mmol} / \mathrm{L}$ isopropyl-1-thio- $\beta$-D-galactopyranoside for $2 \mathrm{~h}$. The bacterial cells were harvested after centrifugation at $8000 \mathrm{~g}$ for $10 \mathrm{~min}$, and the resulting pellets were resuspended in a lysis buffer $(50 \mathrm{mmol} / \mathrm{L}$ sodium phosphate $(\mathrm{pH} 7.8)$, $300 \mathrm{mmol} / \mathrm{L} \mathrm{NaCl}$ ) prior to sonication. Cell lysates were then centrifuged at $10000 \mathrm{~g}$ for $20 \mathrm{~min}$, and the supernatants, which contained soluble proteins, were purified with affinity chromatography using Ni-nitrilotriacetic acid resin (Ni-NTA) (Qiagen, Valencia, Calif.), in accordance with manufacturer's instructions. The Ni-purified proteins were then concentrated on Centricon spin columns and chromatographed on Superose- 
12 columns, using an FPLC facility (Pharmacia, Pont-Viau, Que.).

\section{SDS-PAGE and Western Blot analysis}

SDS-PAGE was performed as described by Laemmli (1970), using $12 \%$ polyacrylamide gels. After electrophoresis, proteins were transferred onto nitrocellulose membranes, following the BioRad semi-dry Trans-Blot apparatus protocol (BioRad, Hercules, Calif.). The blots were then incubated in the presence of polyclonal antibodies raised against rFOMT3' (Séguin et al. 1998), and the protein bands were revealed when nitroblue tetrazolium and 5-bromo-4-chloro-3-indolyl phosphate were used as substrates.

\section{Photoaffinity labeling}

Photoaffinity labeling was performed as described elsewhere (Som and Friedman 1990), using 100 pmol of the purified enzyme protein and $4.5 \mathrm{pmol}$ of neutralized $\left[{ }^{14} \mathrm{CH}_{3}\right]$ AdoMet (American Radiochemicals, Madison) mixed in the well of a multiwell microtiter plate. The samples were placed on ice and exposed to ultraviolet B light $(266 \mathrm{~nm})$ for $30 \mathrm{~min}$. The crosslinking reaction was stopped by adding the SDS-PAGE sample loading buffer, heated to $100{ }^{\circ} \mathrm{C}$ for $2 \mathrm{~min}$, and loaded on a $12 \%$ SDS-PAGE gel. Following electrophoresis, the gel was stained with Coomassie blue (R-250), dried, and exposed to x-ray film to analyze the extent of labeling by fluorography.

\section{Circular dichroism spectroscopy}

Circular dichroic (CD) spectra were measured in $50 \mathrm{mmol} / \mathrm{L}$ sodium phosphate $(\mathrm{pH} 7.8), 300 \mathrm{mmol} / \mathrm{L} \mathrm{NaCl}$, $10 \mathrm{mmol} / \mathrm{L}$ EDTA, $10 \%$ glycerol, and $14 \mathrm{mmol} / \mathrm{L} \beta-$ mercaptoethanol, using a Jasco model 417 spectrometer that operated at $25{ }^{\circ} \mathrm{C}$ between 260 and $200 \mathrm{~nm}$. The machine settings were as follows: resolution, $0.1 \mathrm{~nm}$; scan speed, $20 \mathrm{~nm} / \mathrm{min}$; spectral bandwidth, $1.0 \mathrm{~nm}$; response time, $0.5 \mathrm{~s}$; sensitivity, 100 mdegree. Twenty spectra were accumulated and averaged, from which was subtracted the buffer blank that had been treated identically.

\section{Isothermal titration calorimetry}

The Superose-12 purified proteins were dialyzed over night, during which the assay buffer $(50 \mathrm{mmol} / \mathrm{L}$ sodium phosphate (pH 7.8), $300 \mathrm{mmol} / \mathrm{L} \mathrm{NaCl}, 10 \mathrm{mmol} / \mathrm{L}^{-1}$ EDTA, $10 \%$ glycerol, and $14 \mathrm{mmol} / \mathrm{L} \beta$-mercaptoethanol) was changed three times; AdoMet was diluted in the final dialysis buffer. Isothermal titration calorimetry (ITC) was performed with a Microcal VP-ITC calorimeter, operating at about $15{ }^{\circ} \mathrm{C}$. The protein concentration was $12 \mu \mathrm{mol} / \mathrm{L}$ for the wild-type (FOMT3') enzyme, and $10 \mu \mathrm{mol} / \mathrm{L}$ for the mutant (Ser286Arg) enzyme. The concentration of AdoMet in the injection syringe was $1 \mathrm{mmol} / \mathrm{L}$. The conditions were such that the binding of AdoMet to the wild type was easily detected, but no significant binding to the mutant was detected. The data were analyzed with Origin software (Northhampton, Mass.).

\section{OMT assays and estimation of protein concentration}

Enzyme assays were carried out as described elsewhere (De Luca and Ibrahim 1985); the Superose-12 fractions were mixed with $50 \mu \mathrm{mol} / \mathrm{L}$ of TMQ as the substrate, and $\left[{ }^{14} \mathrm{CH}_{3}\right]$ AdoMet as the cosubstrate. After incubation at $30{ }^{\circ} \mathrm{C}$ for $30 \mathrm{~min}$ and extraction with ethyl acetate, using liquid scintillation spectrometry, the radioactivity in the product was determined. Identity of the methylated product was determined using cochromatography, with reference compounds on TLC and autoradiography. Protein concentration was estimated with the method of Bradford (1976), using the BioRad protein assay kit and bovine serum albumin as the standard protein.

\section{Molecular modeling}

Molecular modelling calculations were conducted on an O2 R12,000 Silicon Graphics workstation, using InsightII modeling software (Accelrys, San Diego, Calif.). The forcefield used for molecular dynamics and energy minimization was cvff, and was provided by Accelrys. The sequence of the template protein, ChOMT (PDB1FPQ), was extracted and aligned with the target protein, FOMT3'. The structurally conserved regions were determined and used to align the sequences. The conformations of side chains were determined with a conformational search of rotamers. The protein was embedded in a 5 - $\AA$ shell of 1888 water molecules to imitate aqueous solvent conditions. The assembled molecules were subjected to energy minimization using the InsightIIDiscover module. Steepest descents were carried out to a maximum derivative of $1.0 \mathrm{kcal} / \mathrm{mol} \AA$, and conjugate gradients were followed to a maximum derivative of $0.1 \mathrm{kcal} / \mathrm{mol} \AA$. After energy minimization, molecular dynamics was performed at $300 \mathrm{~K}$ for $500 \mathrm{ps}$, with 1 fs for each step. The output conformers were collected every 4 ps, and 125 conformers were saved in the history file. The energy profile was analyzed using the InsightII analysis module. For statistical analysis of the conformer, PROCHECK was applied. To obtain a homodimer, the enzyme was used the same as the ligand and the protein. The protein considered to be a ligand was docked into the other protein, using the InsightII docking module. The ligand and protein assembley created using the grid docking method was subjected to energy minimization, and molecular dynamics was performed at $300 \mathrm{~K}$, for $500 \mathrm{ps,}$ with 1 fs for each step.

\section{Results}

\section{Expression of OMT activity of wild-type and mutant enzymes}

Recombinant proteins carrying polyhistidine tags were produced in $E$. coli transformed with pTRCHisC. After affinity chromatography on a Ni-column, followed by gel filtration on Superose-12, both the wild-type (FOMT3') and Ser286Arg mutant proteins were highly purified, to ca. $80 \%$; they were then used for enzyme assays and physicochemical studies. Because other mutant proteins exhibited minute or no enzyme activity, they were assayed in crude lysates, after desalting on PD-10 columns. Crude lysates (Fig. 2, lanes B to $\mathrm{G}$ ) and affinity-purified proteins (Fig. 2, lanes $\mathrm{H}$ and I) migrated at $42 \mathrm{kDa}$ in SDS-PAGE and were immunorecognized by the anti-FOMT3' antibody (Fig. 2, bottom). The level of expression of the mutant enzymes did not differ significantly from that of the wild type, as revealed by their protein content and Western Blot analysis (Table 1, Fig. 2), 
Fig. 2. Top: SDS-PAGE of wild-type (FOMT3') and mutant proteins. The proteins were obtained from crude bacterial lysates, desalted on PD-10 columns, and $10 \mu \mathrm{g}$ of each was loaded on $12 \%$ gel and stained with Coomassie blue (R-250). Lanes: A, Protein markers (kDa); B, FOMT3'; C, FOMT265Arg; D, FOMT286Ala; E, FOMT286Leu; F, FOMTe86Lys; G, FOMT286Thr; H and I, FOMT3' and FOMT286Arg after affinity purification, respectively, $2 \mu \mathrm{g}$ each. Bottom: Western Blot analysis. The immunoreaction was revealed with the anti-FOMT3' antiserum.

$\begin{array}{lllllllll}\text { A } & \text { B } & \text { C } & \text { D } & \text { E } & \text { F } & \text { G } & \text { H } & \text { I }\end{array}$

$42 \mathrm{kDa}$
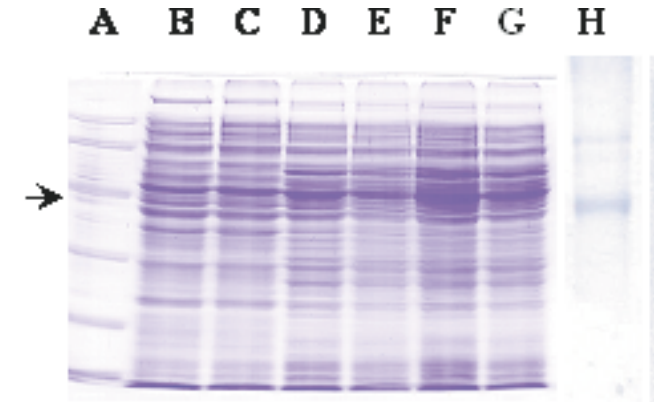

$42 \mathrm{kDa}$

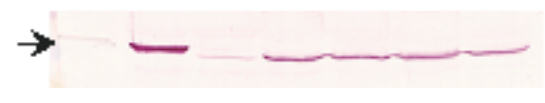

Table 1. Characteristics of the wild-type FOMT3' and its mutant proteins.

\begin{tabular}{lll}
\hline FOMT & $\begin{array}{l}\text { Level of expression } \\
(\mathrm{mg} / \mathrm{L} \text { of medium) }\end{array}$ & $\begin{array}{l}\text { Enzyme activity }^{c} \\
\text { (\% of wild type) }\end{array}$ \\
\hline Ser 286 (FOMT3) ${ }^{a}$ & 19 & $100^{\mathrm{d}}$ \\
Arg 286 (FOMTx) & \\
Leu 286 & 18 & 0.05 \\
Lys 286 & 22 & 0.04 \\
Ala 286 & 20 & 0 \\
Thr 286 & 18 & 0 \\
\hline
\end{tabular}

\footnotetext{
${ }^{a, b}$ Performed with purified proteins and crude bacterial lysates after desalting on PD-10 columns, respectively.

${ }^{c}$ Enzyme activity assayed (in pkat $/ \mathrm{mg}$ ), as described in Materials and methods section and represented in pkat/mg.

${ }^{d}$ Activity of the wild-type enzyme, FOMT3', amounts to $82 \mathrm{pkat} / \mathrm{mg}$.
}

indicating that the point mutations did not affect the level of protein expression.

FOMT3' and Ser286Arg, which differ by one amino-acid residue (Ser 286Arg 286) in their protein sequence (Fig. 1), exhibit distinctly different OMT activities toward TMQ as a substrate; FOMT3'is catalytically active but Ser286Arg is not (Table 1). Replacing Ser 286 in the wild-type enzyme with Arg drastically decreased its catalytic activity, whereas replacing the Arg 286 in FOMTx with Ser restored about $50 \%$ of the enzyme activity of this otherwise catalytically inactive protein (data not shown).

To better understand the regiospecificities of FOMTs, we performed various site-directed mutagenesis to produce FOMTArg, -Ala, -Leu, -Lys, and -Thr mutants. However, none of these mutant proteins exhibited any significant OMT activity against TMQ (Table 1) or any of the other flavonoid substrates tested. Serine is a smaller amino-acid residue than
Fig. 3. Circular dichroism (CD) spectra of affinity-purified FOMT3' (solid line) and FOMTx-Arg (dotted line), measured on a Jasco model 417 spectrometer between 260 and $200 \mathrm{~nm}$.

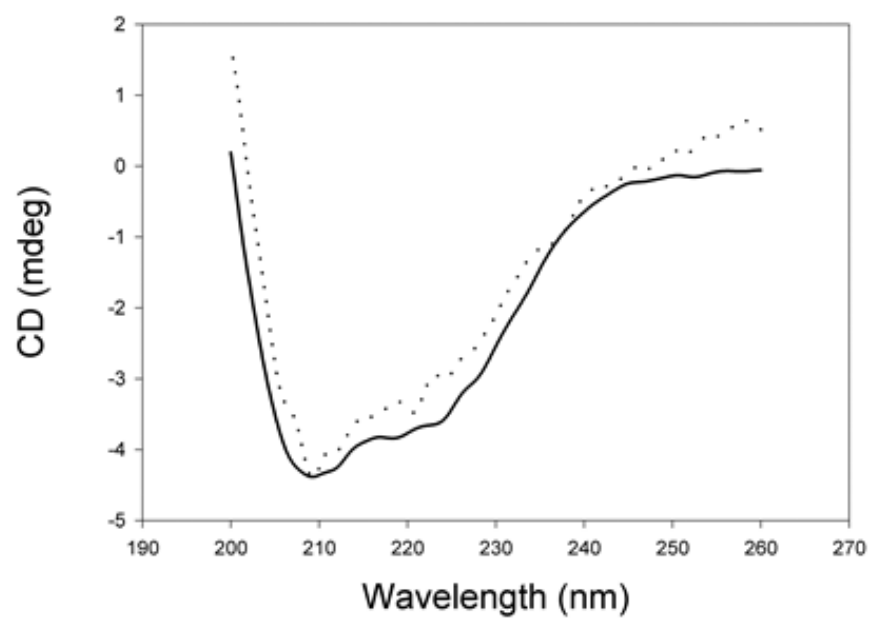

Thr, Arg, Leu, and Lys, but slightly larger than Ala. It is also hydrophilic, as are Arg and Lys, but the latter two are substantially larger and charged. Substituting Ser 286 with any of the latter amino acids may alter the net charge or the packing in this region of the protein and render the active site unavailable for catalysis.

\section{Circular dichroism spectra}

The CD results (Fig. 3) clearly show that the spectra of the wild-type FOMT3' and the mutant Ser286Arg are similar in the peptide-bond region, and display a characteristic minimum at $208 \mathrm{~nm}$. This indicates that the replacement of Ser 286 in FOMT3' with Arg in FOMTx caused no significant disruption in the overall folding pattern (secondary structure) of the protein.

\section{Isothermal titration calorimetry}

The binding of AdoMet to both the wild-type and mutant proteins was monitered by ITC. Figure 4 shows that the wild-type protein, FOMT3', binds AdoMet, whereas the mutant protein, Ser286Arg, does not. The association constants for AdoMet binding and the binding stoichiometry for both proteins are shown in Table 2 . Binding is driven primarily by the entropy change that results from water loss from the AdoMet- and the FOMT3'-binding site.

\section{Photoaffinity labeling}

Figure 5 shows that only the wild-type protein binds the cosubstrate where the photolabeled product migrated at the expected $42 \mathrm{kDa}$. However, the presence of other bands may be due to other proteins that use AdoMet in the affinitypurified fraction. These results corroborate the ITC data (Fig. 4) and suggest that Ser 286 plays a critical role in the AdoMet binding and catalytic activity of FOMT3'.

\section{Molecular modeling}

FOMT3' was modeled on the homologous protein chalcone OMT (PDB1FPQ). ChOMT is a dimer as, most probably, is FOMT3'. Ser286 is far from both the AdoMet-binding site and the active site of the subunit in which it is located 
Table 2. Isothermal calorimetric analysis of FOMT3' and FOMTx proteins.

\begin{tabular}{lll}
\hline Thermodynamic parameters & FOMT3' & Ser286Arg \\
\hline AdoMet-binding stoichiometry (mol AdoMet/mol protein) & 1.029 & N.D. \\
Association constant (mol/L) & $1.8 \times 10^{5}$ & - \\
$\Delta \mathrm{H}\left(\mathrm{cal} . \mathrm{mol}^{-1}\right)$ & -2000 & - \\
$\Delta \mathrm{S}\left(\mathrm{cal} . \mathrm{mol}^{-1}\right)$ & 17 & -
\end{tabular}

Note: N.D., not detected.

Fig. 4. Isothermal titration calorimetry of affinity-purified FOMT3' $^{\prime}(12 \mu \mathrm{mol} / \mathrm{L}$, solid circles $)$ and FOMTx-Arg $(10 \mu \mathrm{mol} / \mathrm{L}$, open circles) that were dialyzed against the assay buffer. The titrant was $1 \mathrm{mmol} / \mathrm{L}$ AdoMet.

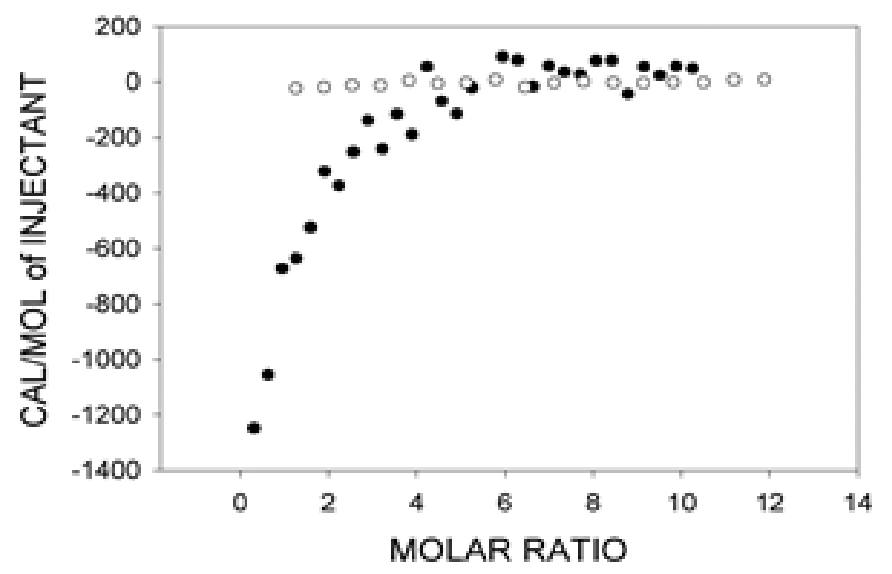

Fig. 5. Photoaffinity labeling of 100 pmol each of the affinity-purified FOMT3' and FOMTx-Arg proteins together with 45 pmol of the neutralized $\left[{ }^{14} \mathrm{CH}_{3}\right]$ AdoMet. The mixture was irradiated under ultraviolet-B light for $30 \mathrm{~min}$ at $4{ }^{\circ} \mathrm{C}$, electrophoresed in $12 \%$ SDS-PAGE, stained with Coomassie blue (R-250), then dried before autoradiography on x-ray film.

\section{FOMT3' Ser286Arg}

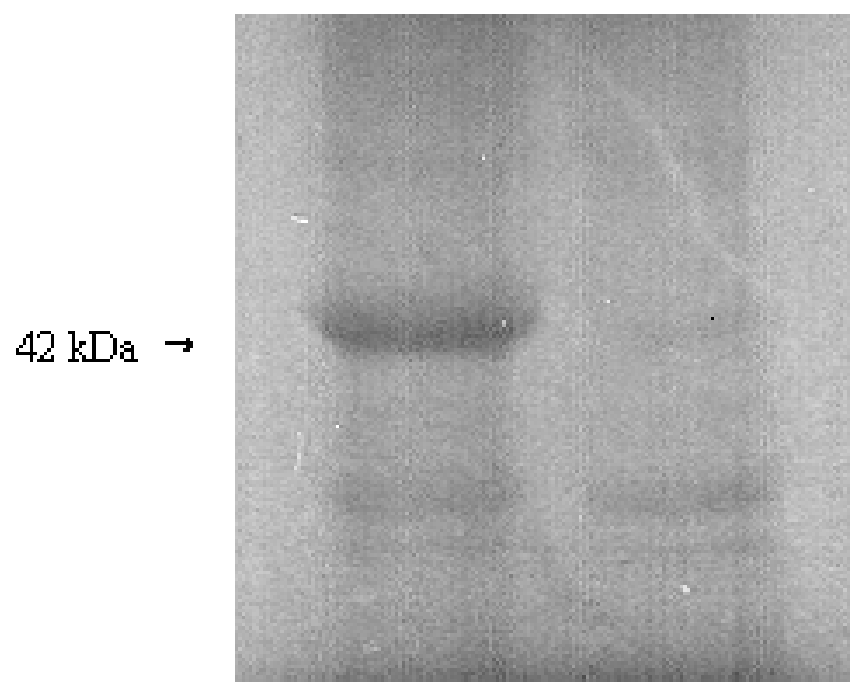

(Fig. 6). The only active-site residue within $10 \AA$ of Ser 286 is Ala292. Met295, Ile296, and Phe159 are within $13 \AA$. These distances are not consistent with Ser286 exerting a direct influence on binding and catalysis within the same
Fig. 6. The FOMT3' dimer. The dimeric structure of the protein was modeled on ChOMT (PDB1FPQ). The active-site residues are shown in orange spacefilling, the AdoMet-binding pocket residues are shown in green, Ser286 in blue, and Ser9 in yellow. The remaining portions of the protein are shown in backbone trace red (one subunit) or blue (the second subunit).

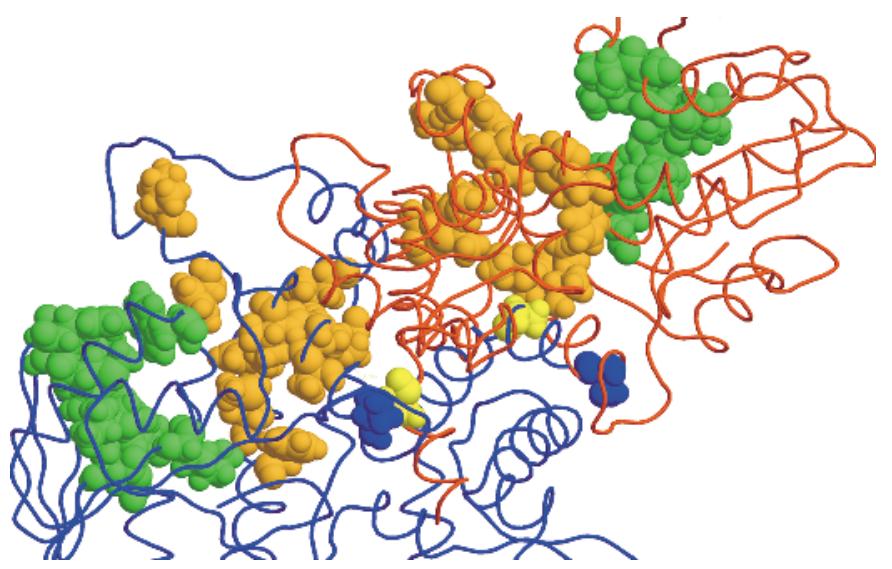

Fig. 7. The relative positions of Ser286 on one monomer (monomer 1) of FOMT3' and the active site and AdoMet-binding site on the second monomer (monomer 2). Ser286 of monomer 1 is shown in red spacefilling. The active site of monomer 2 is shown in green spacefilling, the AdoMet-binding site in orange, and Ser286 in yellow. The remainder of monomer 2 is shown in a backbone trace representation. The remainder of monomer 1 is not shown.

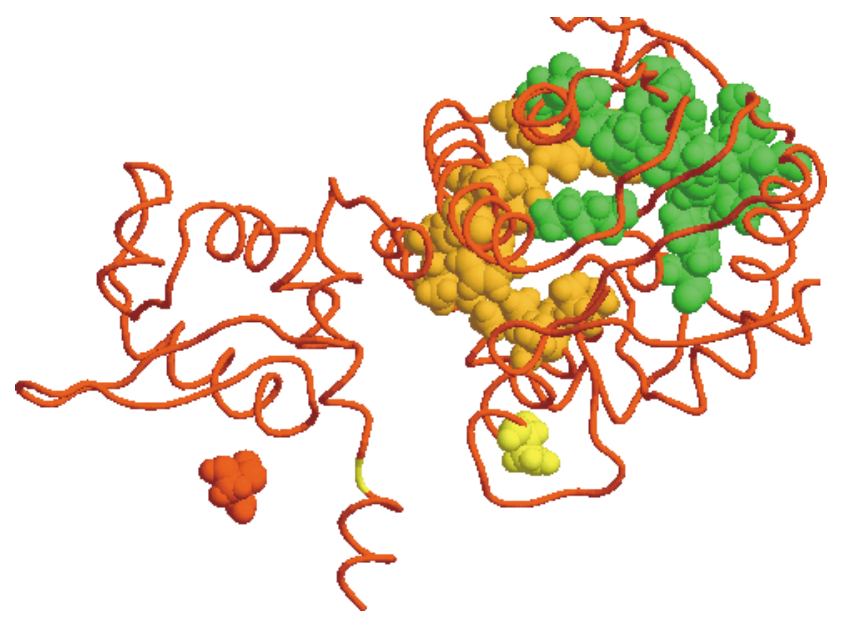

subunit. Ser286 is also far from the AdoMet-binding site and the active site on the opposing subunit; none of the binding residues or active-site residues are within $20 \AA$ of the opposing subunit serine (Fig. 7). The dimer interface of FOMT3' is 
Fig. 8. The dimer interface of FOMT3'. One monomer (monomer 1) is shown in red spacefilling. The orange residues are part of its active site, the green residues form its AdoMet-binding site. The blue and yellow (Ser286) residues are from the second monomer (monomer 2). The only residues of monomer 2 that are shown are those that are within $3.0 \AA$ of monomer 1 . These include the majority of residues between 276 and 290. The importance of these residues stems from the fact that they provide an intimate and extended network that can reduce catalytic activity and binding when interactions between the monomers are disrupted by mutations in residue 286. These disruptions could result from the introduction of bulky residues or from the introduction of charge.

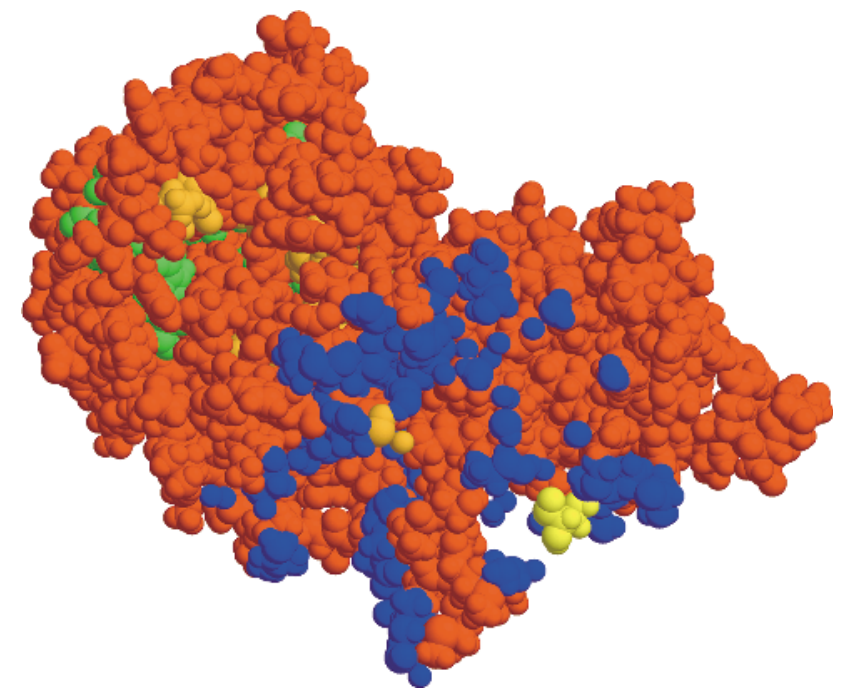

more complex and more irregular than that of most homodimers. The interfacial region is shown in Fig. 8. Of the residues from interfacial atoms, amino acids 276 to 290 are within $3.0 \AA$ of the opposing subunit. This means that Ser286 has intimate communication with this opposing subunit via the backbone on each side of Ser286.

\section{Discussion}

There have been several reports in the literature in which a single amino-acid substitution resulted in the inactivation of enzyme activity or the alteration of substrate specificity/ preference. The Ser286Arg mutation in FOMT3' and FOMTx represents the first reported instance among the enzymes involved in flavonoid biosynthesis in which a single invariant amino-acid change results in the loss of catalytic activity of a FOMT. The fact that all of the Ala, Leu, Lys, and Thr mutant proteins displayed no measurable catalytic activity with TMQ as a substrate, with either ITC measurements or photoaffinity labeling, indicates that Ser286 plays a critical role in AdoMet binding and catalysis. This is further supported by the fact that the gene products of two other C. americanum cDNA clones, FOMTm and FOMTn (Fig. 1), where Ser286 is replaced with Thr, do not accept TMQ as a substrate. In fact, both gene products exhibit a certain degree of promiscuity, by differentially catalyzing the 3'-O-methylation of luteolin (a flavone) and quercetin (a flavonol), and the 3/5- $O$-methylation of the phenylpropanoids, caffeic acid, and 5-hydroxyferulic acid (Gauthier et al. 1998).

Most OMTs, such as the chalcone $2^{\prime}$ and the isoflavone 7
OMTs (Zubieta et al. 2001), and the caffeic-acid OMT (Zubieta et al. 2002), exist in solution as homodimers, as most probably does FOMT3'. Using ChOMT as a template, the role of Ser286 in cosubstrate binding and catalysis in FOMT3' cannot be explained on the basis of a direct positive effect; Ser286 is too far from the binding pocket and the active site to directly influence binding and catalysis.

FOMT3' modeling on the coordinates of ChOMT indicates that Ser286 is more than $20 \AA$ away from the $S$-adenosyl-Lhomocysteine (SAH) binding pocket, and from SAH itself (data not shown). Comparison of FOMT3' and Ser286Arg monomers indicates that the mutation induces no obvious differences in the SAH-binding sites of either protein. At a distance of $20 \AA$, substantial changes are not likely, except when the protein undergoes a major conformational change, which is not the case here, evidenced by the CD spectra. ChOMT is clearly a dimer. FOMT3' must also be a dimer. At the interface of the ChOMT, FOMT3' has 50\% identity. At the interface of caffeic-acid OMT, clearly a dimer in the crystal structure, FOMT3' has $>80 \%$ identity. We performed homology modeling on ChOMT and caffeic-acid OMT, which showed a $47 \%$ sequence identity. The two proteins had similar overall folding patterns, and the dimer interfaces aligned extremely well. It appears that most plant OMTs share structural and catalytic characteristics (Schubert et al. 2003). Therefore, disruption of the FOMT3' homodimer would compromise the overall catalytic process and the binding of AdoMet. Dimer integrity is necessary for other enzymes. Rabbit muscle enolase is a homodimer in which dissociation causes a loss of activity without disrupting the overall secondary structure of the monomers (Kornblatt et al. 1996). Chemical dissociation of the enolase causes a loss of activity, although its CD spectrum in the far ultraviolet range remains unchanged. Mutations in the dimer interface cause a loss of dimeric structure and catalytic activity, but no loss in the far-ultraviolet CD (M. J. Kornblatt, personal communication, 2003). The parallels between enolase and FOMT3' are striking.

\section{Acknowledgements}

This work was supported by grants from the Natural Sciences and Engineering Research Council of Canada to both J.A.K. and R.K.I., and the Korea Ministry of Science and Technology to J.H.A. We wish to thank Dr. Jean Danyluk for his help in constructing the mutants used in this work.

\section{References}

Bohm, B.A. 1998. Flavonoid functions in nature. In Introduction to flavonoids. Chemistry and biochemistry of organic natural products. Vol. 2. HarwoodAcademic Publishers, Amsterdam, Netherlands. pp. 339-364.

Bradford, M.M. 1976. A rapid and sensitive method for the quantitation of microgram quantities of protein utilizing the principle of protein-dye binding. Anal. Biochem. 72: 248-254.

De Luca, V., and Ibrahim, R.K. 1985. Enzymatic synthesis of polymethylated flavonols in Chrysosplenium americanum. I. Partial purification and some properties of 3-, 6-, 7- and 4'- $O$-methyltransferases. Arch. Biochem. Biophys. 238: 496-605.

French, C.J., Elder, M., Leggett, F., Ibrahim, R.K., and Towers, 
G.H.N. 1991. Flavonoids inhibit mosaic virus infectivity. Can. J. Plant Pathol. 13: 1-6.

Gauthier, A., Gulick, P.G., and Ibrahim, R.K. 1996. cDNA cloning and characterization of an $S$-adenosyl-L-methionine:partially methylated flavonal 3'/5'-O-methylransferase from Chrysosplenium americanum. Plant Mol. Biol. 32: 1163-1169.

Gauthier, A., Gulick, P.G., and Ibrahim, R.K. 1998. Characterization of two cDNA clones which encode $O$-methyltransferases for the methylation of both flavonoid and phenylpropanoid compounds. Arch. Biochem. Biophys. 351: 243-249.

Hofsteenge, J., Moldow, C., Vicentini, A.M., Jarai-Kote, Z., and Neumann, U. 1998. A single amino acid substitution changes ribonuclease 4 from a uridine-specific to a cytidine-specific enzyme. Biochemistry, 37: 9250-9257.

Hu, T., Chang, S., and Hsieh, T. 1988. Identifying Lys359 as a critical residue for the ATP-dependent reactions of Drosophila DNA topoisomerase II. J. Biol. Chem. 273: 9586-9592.

Ibrahim, R.K., and Muzac, I. 2000. The methyltransferase gene superfamily: a tree with multiple branches. In Evolution of metabolic pathways. Edited by J.T. Romeo, R.K. Ibrahim, L, Varin, and V. De Luca. Pergamon, Amsterdam, Netherlands. pp. 349-384.

Iwano, H., Yokota, H., Ohgiya, S., Yotumoto, N., and Yuasa, A. 1997. A critical amino acid residue, Asp446 in UDP-glucuronosyltransferase. Biochem. J. 325: 587-591.

Johnson, E.T., Ryu, S, Yi, H., Shin, B., Cheong, H., and Choi, G. 2001. Alteration of a single amino acid changes the substrate specificity of dihydroflavonol 4-reductase. Plant J. 25: 325-333.

Kittendorf, J.D., Sgraja, T., Reuter, K., Klebe, G., and Garcia, G.A. 2003. An essential role for aspartate 264 in catalysis by tRNA-guanine transglycosylase from Escherichia coli. J. Biol. Chem. 278: 42369 - 42376.

Kornblatt, M.J., Al-Ghanim, A., and Kornblatt, J.A. 1996. The effects of sodium perchlorate on rabbit muscle enolase. Spectral characterization of the monomer. Eur. J. Biochem. 236: 78-84.

Laemmli, U.K. 1970. Cleavage of structural proteins during the assembly of the head of bacteriophage T4. Nature, 227: 668685.

Mayer, C., Zechel, D.L., Reid, S.P., Warren, R.A., and Withers,
S.G. 2000. The E358S mutant of Agrobacterium sp. $\beta$-glucosidase is a gratly improved glycosynthase. FEBS Lett. 466: 40-44.

McKinney, M.K., and Cravatt, B.F. 2003. Evidence for distinct roles in catalysis for residues of the Serine-Serine-Lysine catalytic triad of fatty acid amide hydrolase. J. Biol. Chem. 278: 37393 37399.

Pollock, V.V., and Barber, M.J. 2000. Serine 121 is an essential amino acid for biotin sulfoxide reductase functionality. J. Biol. Chem. 275: 35086 - 35090.

Schröder, G., and Schröder. J. 1992. A single change of histidine to glutamine alters the substrate preference of a stilbene synthase. J. Biol. Chem. 267: 20558 - 20560.

Schubert, H.L., Blumenthal, R.M., and Cheng, X. 2003. Many paths to methyl transfer: a chronicle of convergence. Trends Biochem. Sci. 28: 329-335.

Séguin, J., Muzac, I., and Ibrahim, R.K. 1998. Purification and immunological characterization of a recombinant trimethylflavonol 3'-O-methyltransferase. Phytochemistry (Oxf.), 49: 319-325.

Som, S., and Friedman, S. 1990. Direct photolabeling of Eco RII methyltransferase with $S$-adenosyl-L-methionine. J. Biol. Chem. 265: 4278-4283.

Yamamoto, F., and McNeill, P.D. 1996. Amino acid residue at codon 268 determines both activity and nucleotide-sugar donor substrate specificity of human histo-blood group A and B transferases: in vitro mutagenesis study. J. Biol. Chem. 271: 10515 10520.

Zhu, B.T., Ezell, E.L., and Liehr, J.G. 1994. Catechol-Omethyltransferase-catalyzed rapid $O$-methylation of mutagenic flavonoids. Metabolic inactivation as a possible reason for their lack of carcinogenicity in vivo. J. Biol. Chem. 269: 292-299.

Zubieta, C., He, Xian-Zhi, Dixon, R.A., and Noel, J.P. 2001. Structures of two natural product methyltransferases reveal the basis for substrate specificity in plant $O$-methyltansferases. Nature Struct. Biol. 8: 271-279.

Zubieta, C., Kota, P., Ferrer, J.L., Dixon, R.A., and Noel, J.P. 2002. Structural basis for the modulation of lignin monomer methylation by caffeic acid/5-hydroxyferulic acid 3/5-O-methyltransferase. Plant Cell, 14: 1265-1277. 